\author{
Mirosław Guzik \\ Dr inż. \\ Wydział Transportu i Informatyki, \\ Wyższa Szkoła Ekonomii i Innowacji w Lublinie \\ miroslaw.guzik@wsei.lublin.pl
}

\title{
Piotr Lesiak
}

Dr hab. inż., prof. nadzw. WSEI

Wydział Transportu i Informatyki,

Wyższa Szkoła Ekonomii i Innowacji w Lublinie

piotr.lesiak@wsei.lublin.pl

DOI: 10.35117/A_ENG_19_03_01

\section{Measurement of clips geometry for elements fastening rail to sleepers}

\begin{abstract}
Measuring results of SB4 clips geometry that are used to fasten rails to sleepers have been presented in this paper. The measurements were carried out in compliance with suggestions presented by PKP PLK S.A., with the use of contactless method. This method uses 3D optical scanner along with dedicated software to precisely measure the geometry of the clip. It allowed authors to check if all dimensions of the clip whose parameters are specified in its data sheet are within tolerance limits. It turns out that some dimensions significantly differ from their nominal values. It results from the fact that the geometry of real clips is partially simplified. In the future, authors are going to increase the population of examined clips and the period of observation of the change of their dimensions.
\end{abstract}

Keywords: Railway track; Rail fastening; SB4 clips; 3D scanning

\section{Introduction}

The rail fasteners should ensure that the track width is constant and the rail slopes are inclined, and in the case of concrete sleepers, isolate them from the rail. An important task of fastenings is also damping of vibrations caused by rail vehicles traveling on the track.

The various operational experiences of railroad management translate into a considerable variety of types of fastenings used to fasten rails to railway sleepers $[2,11]$. However, nowadays, elastic type fastenings are increasingly used, which entails the introduction of higher train speeds, including high-speed railways.

PKP PLK S.A. commonly uses elastic fasteners on its modernized railway lines. In the years 1981-2005, only SB3 clips were manufactured and used in the track. Currently, the basic variant is the SB type [4] clip, made in accordance with the European standard [7]. Their numerous operational advantages have been confirmed by national surveys. Their subsequent mutations SB7 and SB8 [1, 6 and 7] are also becoming more and more common. Particularly comprehensive information is provided in the publication [7], where both vibration, noise, and stress distribution parameters in the SB type.

Elastic attachments of various types, also found recipients in railway boards of other countries, where they also conducted extensive thematic research, such as mechanical laboratory tests [8, 9 and 12], including fatigue tests [10] and noise and vibration testing [ 5, 14]. The distribution of stress in the clips was also modeled using the finite element method [13] and geometric deformations and vibrations, supported by in-service track tests [17].

The area of interest of the authors of the article were laboratory measurements of the elastic spring geometry of the SB4, made with an optical 3D scanner, located on the Faculty 
of Transport and Computer Science at the University of Economics and Innovation in Lublin. They fill a significant gap in relation to the guidelines for controlling the geometric dimensions defined in the PKP PLK SA document entitled "Technical conditions for the production and acceptance of elastic clip and springs fixing rails for sleepers and traveling vehicles" NR WTWiO - ILK3D-5183-5 / 2007E.P [4].

\section{The method of research}

The use of direct measurement methods in the case of elements resulting from spatial bending of a thick wire is problematic, which may translate into insufficient measurement accuracy. In the aforementioned document, PKP PLK S.A. [4], there is a protocol for an incomplete examination of the type of clips, which only concerns a few tolerated linear dimensions. However, the bending radii of the wire into spatial and tangent arches are also tolerable dimensions that have not been included in the protocol of incomplete tests, probably because of the difficulty of making such a measurement.

The preliminary character of the tests, limited the tests of SB4 clips to four copies, without the history of their exploitation. To carry out this measurement task, an optical 3D GOM Atos Triple III scanner was used (Fig. 1a) with appropriately selected parameters of the measurement system (Table 1) and GOM Inspect dimensional quality control software [15, 16]. In this way, it was possible to conduct a comprehensive check with high accuracy of all relevant dimensions of the tested clips.

Tab. 1: Parameters of the applied measuring system

\begin{tabular}{|c|c|}
\hline Camera resolution & $2 \times 8 \mathrm{MPx}$ \\
Measurement area & $320 \times 240 \mathrm{~mm}$ \\
Distance points in the cloud & $0,02-0,03 \mathrm{~mm}$ \\
\hline
\end{tabular}

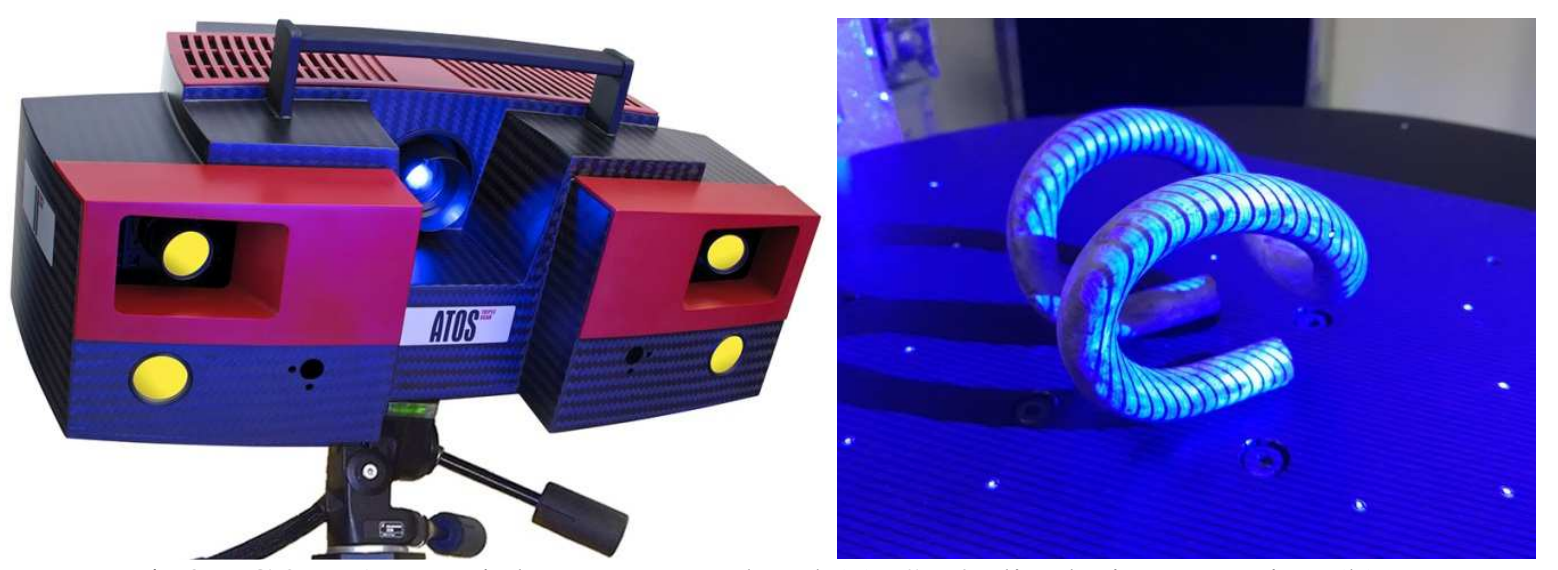

1. 3D GOM Atos Triple III scanner head (a), SB4 clip during scanning (b)

The head of the scanner used consists of two digital cameras and a projector. The measuring system is based on the method of structural light, which consists of a projection of light stripes and simultaneous recording by CCD cameras, operating on the principle of the stereoscopic technique. The system allows you to define several exposure times for cameras, depending on the ambient lighting and surface characteristics of the part being scanned.

The elasticised spring is covered with dark paint and is difficult to scan (Fig. 1b). In this case, a special anti-reflective agent or a matte light-colored paint should be applied to the surface of the part. This is to improve the image quality emitted by the scanner projector by reducing the absorption of light on the surface of the part. However, in order to optimize the process for a longer series of measurements, care has been taken to avoid this problematic stage. The applied solution consisted of the selection of two, respectively extended exposure 
times, which ensured surprisingly good scanning results in these difficult conditions (Figure 2a). The target product of the scan is a triangle grid which, constituting a threedimensional structure, approximates the elementary surfaces of the real object with elementary planes (Fig. 2b).
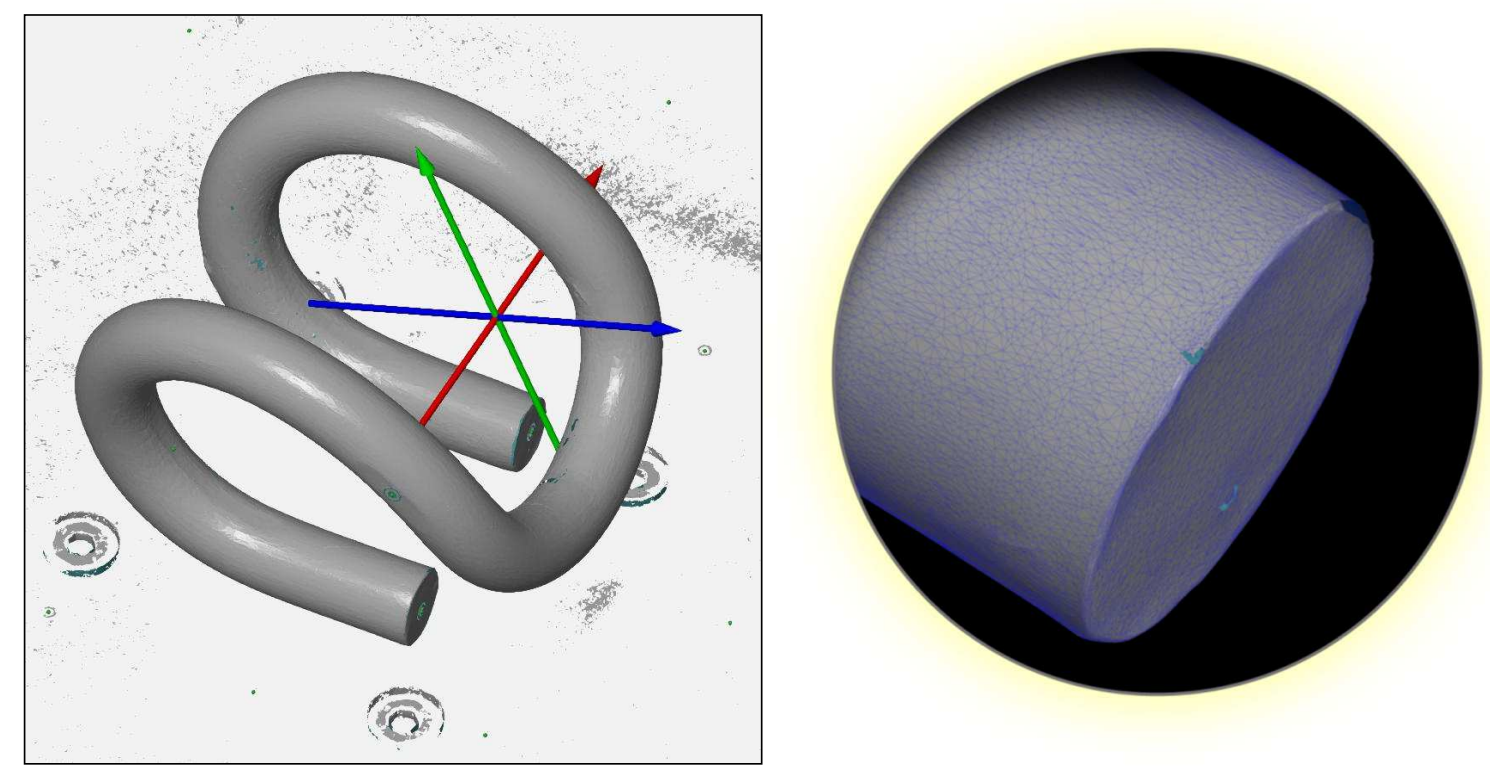

2. The image of the elastic clip obtained as a result of scanning, formed from a mesh of triangles imitating its surface - the effect of a trial scan (a), an enlarged view of the triangle grid of one of the ends of the clip (b)

A rotary table was also used for scanning, enabling partial automation of the process. The scanning of each clip was carried out in two series - in the first place, the clip was scanned all the time in six slides in its natural position, and then in four slides after reversing the bottom. The series were combined using four reference markers (green points in Figure 2b). The described procedure enables effective scanning also in longer measuring series.

In order to perform an appropriate comparative analysis, it was necessary to reconstruct the reference CAD model of the SB4 clip on the basis of technical drawings [4], in relation to the nominal dimensions. For this purpose, the Solid Edge ST software was used [3]. The construction drawing (fig. 3) was made on the basis of the reconstructed CAD model of the SB4 clip, while being in full compliance with the technical documentation. 

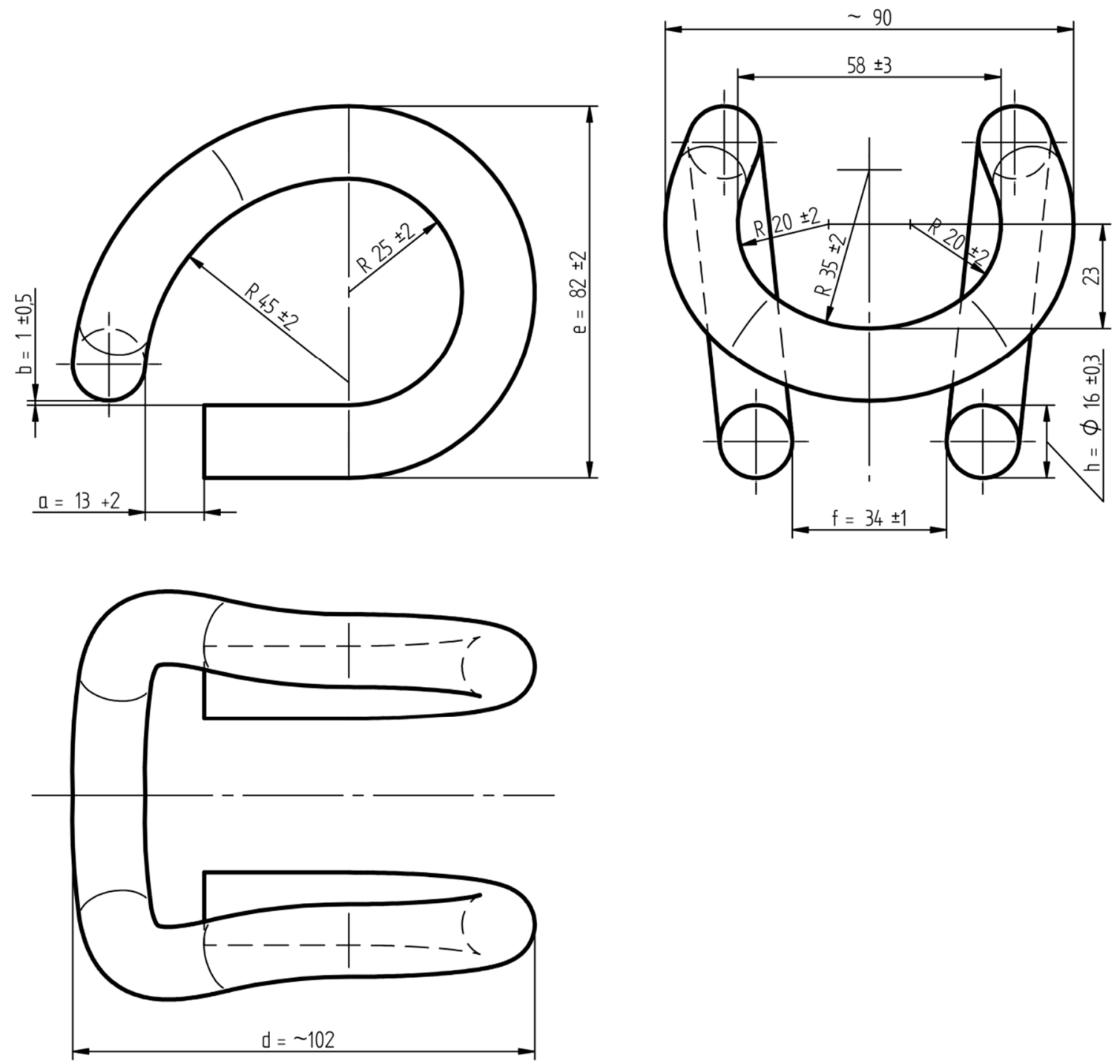

3. Construction drawing of SB4 clips made on the basis of the reconstructed CAD model

Geometric measurements, performed in the software used to control dimensional quality, consist of matching simple geometric elements to the appropriate parts of the scan and building on their basis appropriate structures to determine the actual deviations of tolerated dimensions. The element's adjustment is based on statistical calculations and is always burdened with a certain error resulting from the ambiguity of the interpretation of the approximate shape based on the measurement points. This error depends, of course, on the number of collected measuring points, which the shape is approximated from, but also on the irregularity of the actual shape (e.g. the actual cross-section should be circular and is oval due to plastic deformation or manufacturing error). In order to match geometrical elements, the Gaussian method was used, which is standard in numerical measurements (e.g. using coordinate measuring machines).

An especially important issue in terms of interpretation of the obtained measurement results is the method used to base the triangle mesh obtained as a scan result describing the geometry of the actual object, relative to the reference CAD model, which is the nominal and oriented geometry in the assigned coordinate system. In the guidelines of PKP PLK S.A. [4] for direct measurements, no measurement bases are marked. Therefore, it was necessary to choose the equalization of the compared models, which takes away all degrees of freedom and at the same time best corresponds to the direct measurements of the most important tolerated 
dimensions. It was decided that such homing (figure 4) would be the best fit of the area of the straight ends of the clip, cooperating with the anchoring bolt and matching the frontal crosssection of the arch, cooperating with the rail clip.

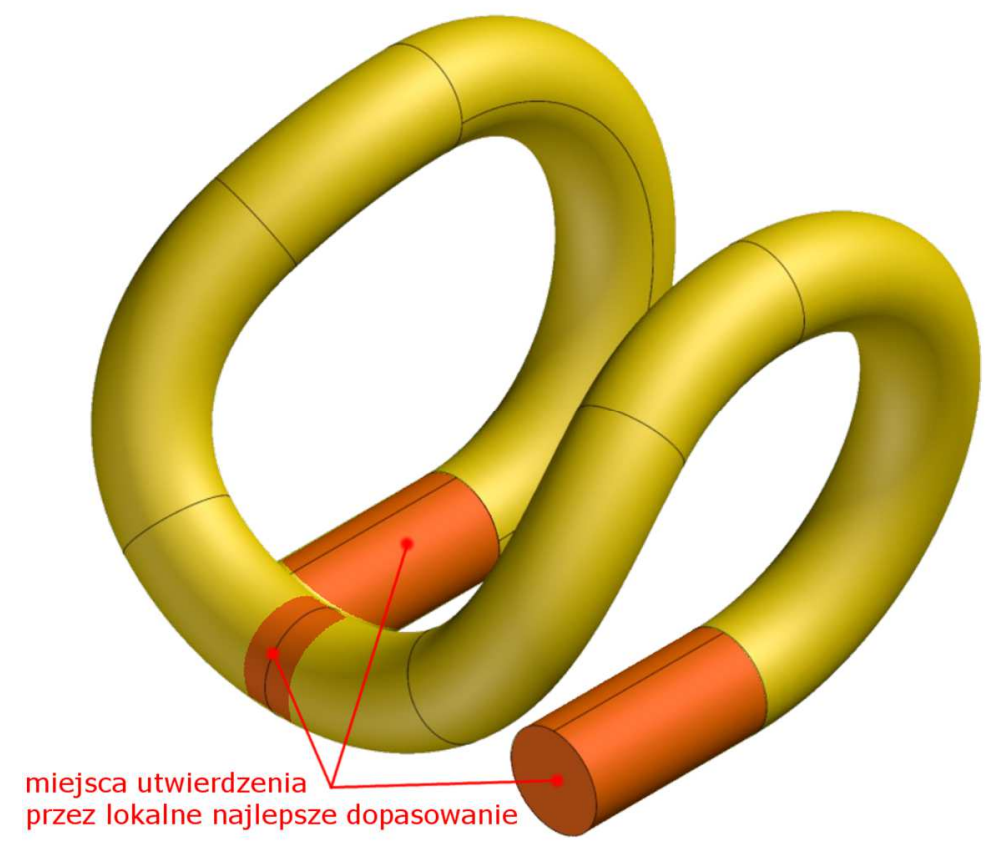

4. The applied method of basing the compared geometries

The GOM Inspect software allows you to define a complete measurement template containing the necessary rules enabling proper homing of the actual object geometry with respect to the nominal model, determining the actual deviations and calculating the deviations of tolerated dimensions. The results are compiled in a graphical and tabular form in a report generated automatically based on a properly defined template. The developed measurement scheme, like the scanning process, provides the required performance of the control process, allowing further extension of the scope of research.

\section{Findings}

The aim of the dimensional quality control carried out in the scope of the preliminary tests described was to draw conclusions regarding the general characteristics of the product and to specify the direction and scope of further research. At this stage, it is impossible to formulate conclusions based on the number of good and bad units in the measured series because it would require extending the research to a correspondingly large population.

Preliminary comparison of the front and top views of the nominal CAD model with the views obtained as a result of the scanning of the real triangle meshes of clips (Figure 5), indicates a significant simplification of the arches in the frontal region. There are no two points of inflection in the actual clips, which in the nominal model are located in the place where the front arc passes into side arches. However, the left and right clip prints are similar to the reference CAD views profile and do not show any anomalies. Similar observations apply to all four measured SB4 clips. 

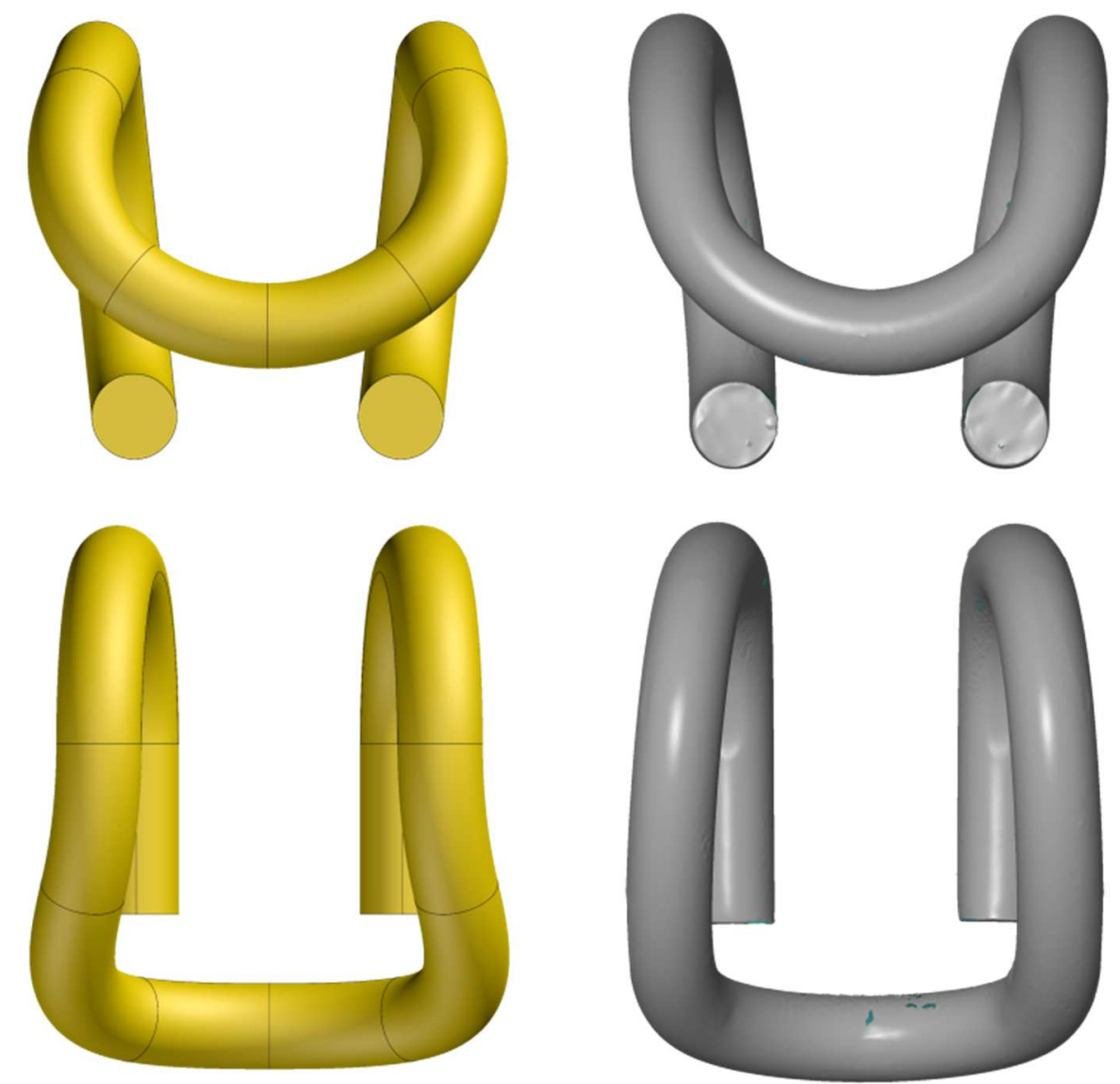

5. Views from the front and from the top - a comparison of the CAD model (on the left) with the real mesh of the clip number 1 (on the right)

The map of geometrical deviations (Fig. 6), resulting from the comparison of properly referenced real triangle meshes with respect to the nominal CAD model, confirms the above observations. The greatest deviations in opposite directions occur symmetrically with respect to the vertical plane around the tops of the arches, the shape of which has been simplified. However, it should be noted that the most important in terms of design and functional areas of the ends of the clips cooperating with the anchor, as well as the area of the leading arch, cooperating with the base of the rail, is in the range of minimal deviations. This is due to the homing adopted for these areas, as well as their good geometric convergence with respect to the nominal model. 

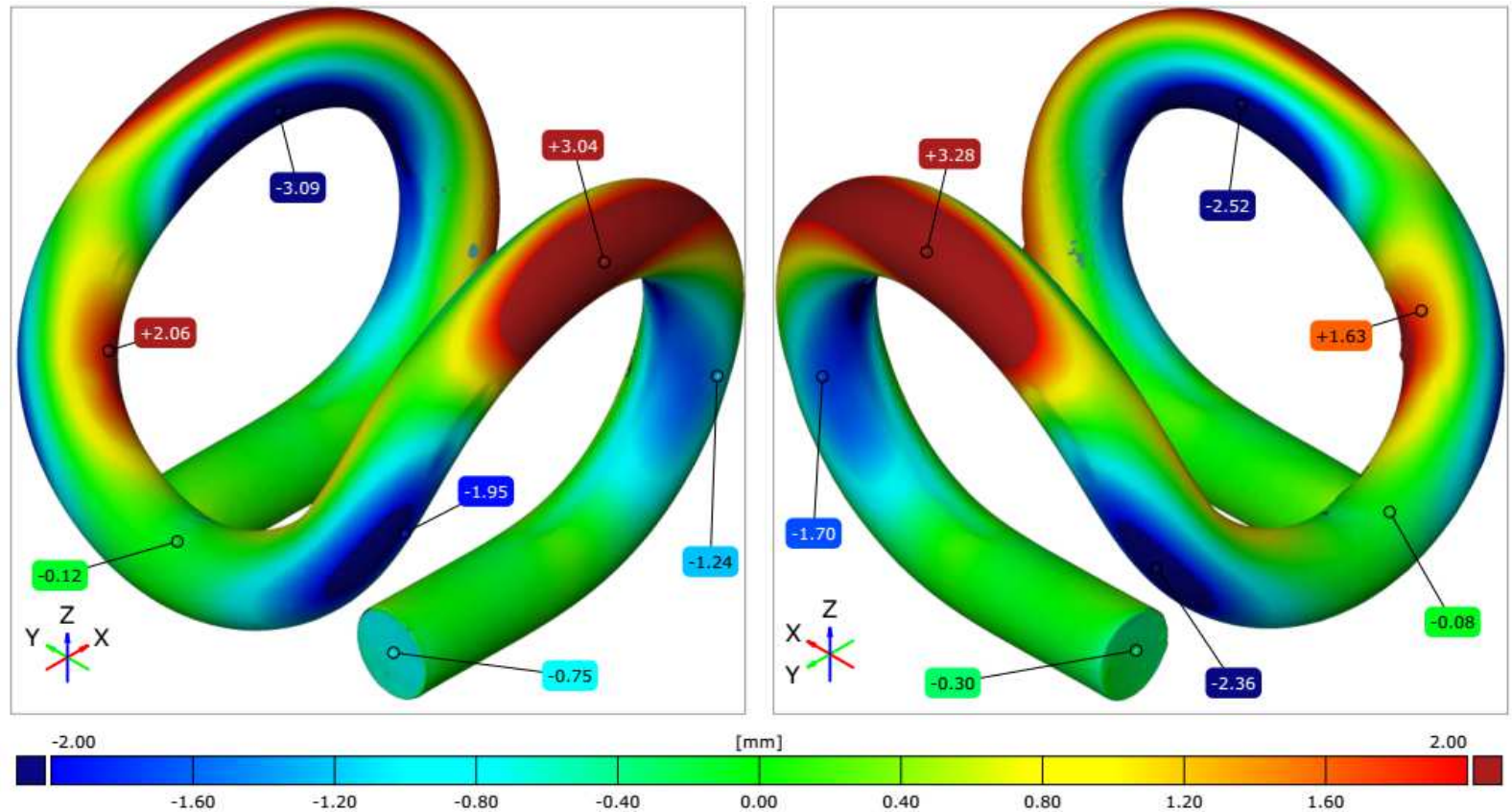

2.00

6. Map of deviations of the scanned clip No. 1 in relation to the nominal shape

As mentioned in the previous section, measuring spatially curved arches with direct methods is quite difficult. Added to this is the difficulty in locating places where one arc passes tangentially into the other. Probably for these reasons, the guidelines of PKP PLK SA do not take into account the measurement of these arcs in the incomplete test report, despite the definition of these dimensions as tolerated. However, by applying the proposed method, these elements can be measured as effectively as others.

The measurement consists in adjusting the circle (Fig. 7, 8) to the clip contour generated in the corresponding view, the length of the adjusted arc being determined based on the relevant areas of the CAD model, where the arc contact points and inflection points are strictly defined. Nevertheless, in the area of side arches with a nominal radius of $20 \mathrm{~mm}$ (Fig. 7) the shape of the clips deviates significantly from the nominal one, that in some measurements the result is unreliable due to a failed fit. In the case of these R20 arcs tolerated in the range of $\pm 2 \mathrm{~mm}$, the deviation is usually around $+14 \mathrm{~mm}$ (Table 2), which can be explained only by a deliberate change in shape by the manufacturer, probably due to technological reasons. The PLK documentation is also not correlated with a frontal arch with a nominal radius of $35 \mathrm{~mm}$, tolerated in the range of $\pm 2 \mathrm{~mm}$, the actual dimensions of which for all measured clips are smaller by an average of $5 \mathrm{~mm}$.

Tab. 2: Set of deviations ( $\mathrm{mm}$ ) of measured radii in the frontal area (not included in the test according to the guidelines of PKP PLK S.A.)

\begin{tabular}{|c|c|c|c|}
\hline $\begin{array}{c}\text { Clip } \\
\text { number }\end{array}$ & $\begin{array}{c}\text { Arc R35, } \\
\text { tol. } \pm 2 \\
\mathrm{~mm}\end{array}$ & $\begin{array}{c}\text { Arc } \\
\text { R20L, } \\
\text { tol. } \pm 2 \\
\mathrm{~mm}\end{array}$ & $\begin{array}{c}\text { Arc } \\
\text { R20P, tol. } \\
\pm 2 \mathrm{~mm}\end{array}$ \\
\hline 1 & $-5,04$ & $+15,66$ & $-3,02$ \\
\hline 2 & $-5,10$ & $+13,38$ & $+13,30$ \\
\hline 3 & $-5,09$ & $+6,78$ & $+14,38$ \\
\hline 4 & $-5,04$ & $+14,51$ & $+32,77$ \\
\hline
\end{tabular}




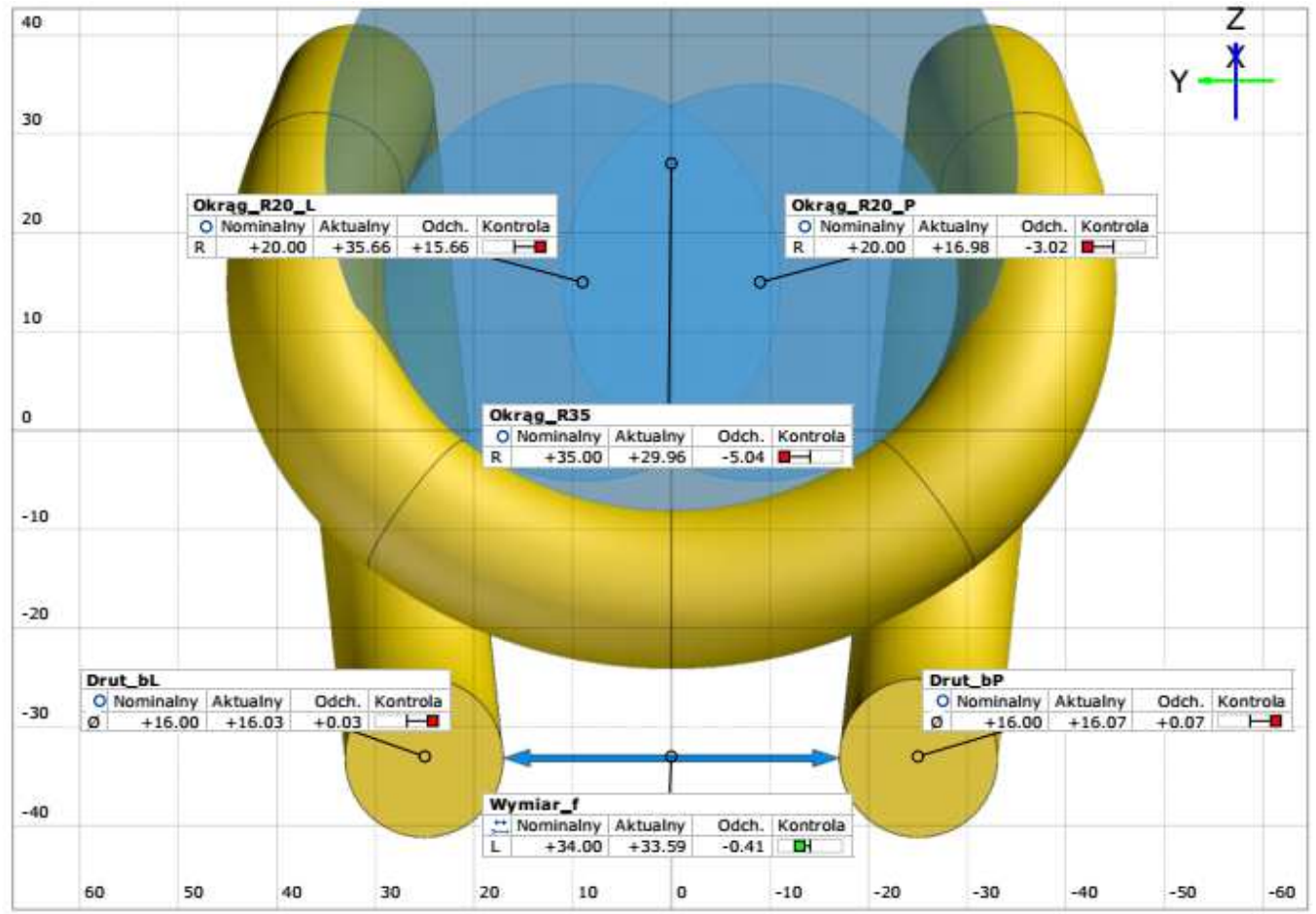

7. The checked dimensions of clip No. 1 are shown in the front view

The results of measurements of successive arcs, visible in the profile from the left $(\mathrm{L})$ or right (P) (Fig. 8) are summarized in Table 3. All dimensions are within the tolerance range, however, some regularity of individual deviations is noticeable. R25 curves are made with a deviation of approx. $+1 \mathrm{~mm}$ on the left side and approx. $+0.9 \mathrm{~mm}$ on the right. However, the deviations of R45 arcs are negative and on both sides, they amount to an average of $-0.8 \mathrm{~mm}$.

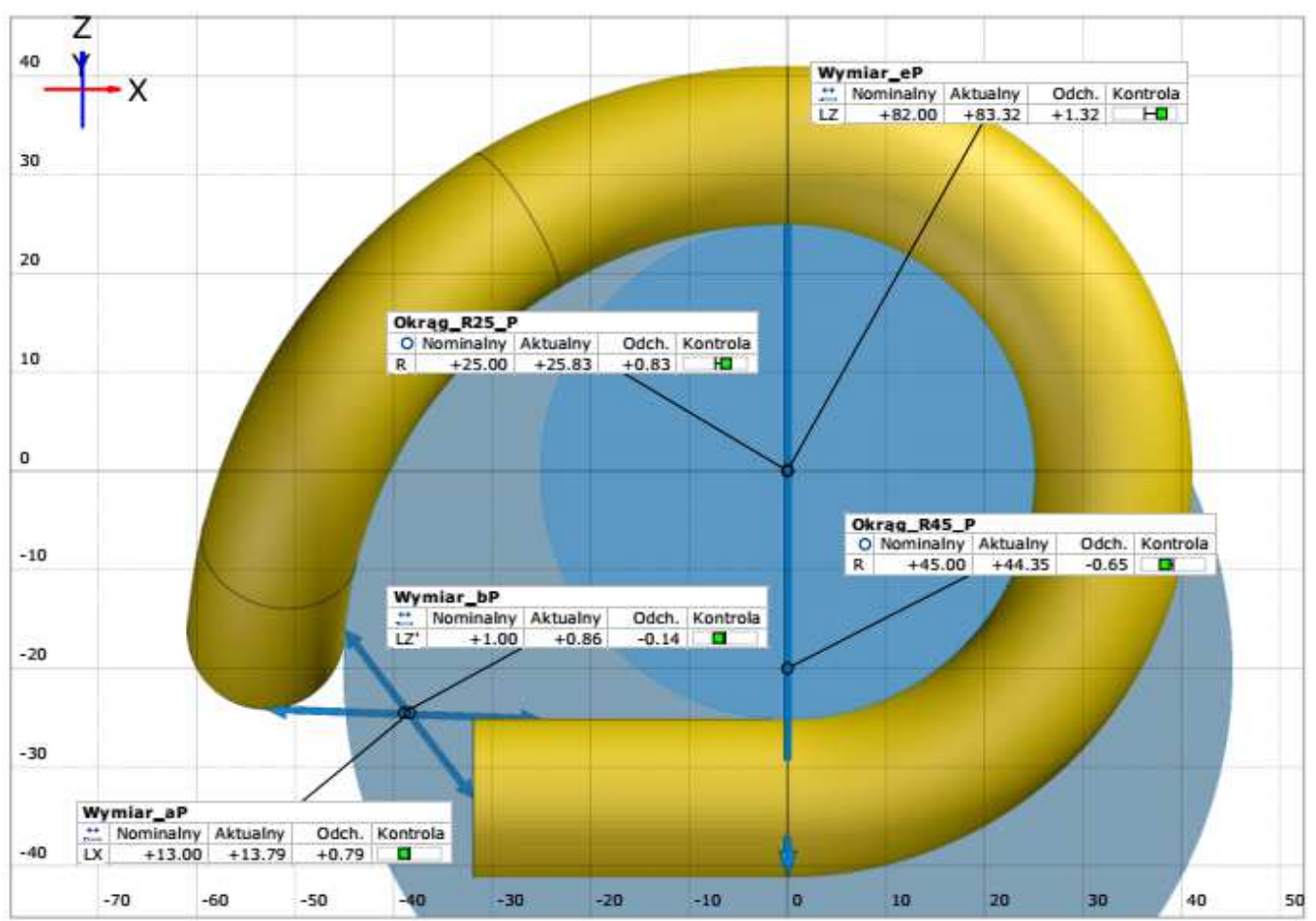

8. The checked dimensions of clip No. 1 are shown in the right view 
Tab. 3: Set of deviations ( $\mathrm{mm}$ ) of measured radii of the clip profiles (not included in the test according to the guidelines of PKP PLK S.A.)

\begin{tabular}{|c|c|c|c|c|}
\hline $\begin{array}{c}\text { Clip } \\
\text { number }\end{array}$ & $\begin{array}{c}\text { Arc } \\
\text { R25L, } \\
\text { tol. } \pm 2 \\
\mathrm{~mm}\end{array}$ & $\begin{array}{c}\text { Arc } \\
\text { R25P, tol. } \\
\pm 2 \mathrm{~mm}\end{array}$ & $\begin{array}{c}\text { Arc } \\
\text { R45L, } \\
\text { tol. } \pm 2 \\
\mathrm{~mm}\end{array}$ & $\begin{array}{c}\text { ArcR45P, } \\
\text { tol. } \pm 2 \\
\mathrm{~mm}\end{array}$ \\
\hline 1 & $+0,90$ & $+0,83$ & $-0,59$ & $-0,65$ \\
\hline 2 & $+0,92$ & $+0,92$ & $-0,79$ & $-1,04$ \\
\hline 3 & $+1,26$ & $+0,95$ & $-0,98$ & $-0,82$ \\
\hline 4 & $+1,04$ & $+0,80$ & $-1,00$ & $-0,82$ \\
\hline
\end{tabular}

Dimensions covered in the document PKP PLK S.A. [4] the protocol of incomplete tests are defined respectively by the letters $a, b, e, f$ (Figures $3,7,8$ ). The results of their measurements are summarized in Table 4. The letters $\mathrm{L}$ or $\mathrm{P}$ denote the dimension of a given length, referring respectively to the left or right view. The measurement of these lengths generally indicates the behavior of the construction dimensions controlled by PKP PLK. Only clip number 3 shows bigger deviations, analysis of which shows that it is slightly bent (increased value of vertical dimensions e and $b$ ).

Tab. 4: List of deviations of measured lengths, defined in the protocol of incomplete tests according to the guidelines of PKP PLK S.A.

\begin{tabular}{|c|c|c|c|c|c|c|c|}
\hline $\begin{array}{l}\text { Clip } \\
\text { numb } \\
\text { er }\end{array}$ & 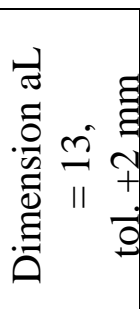 & 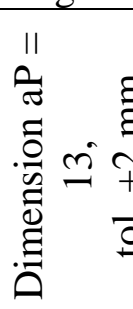 & 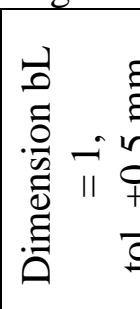 & 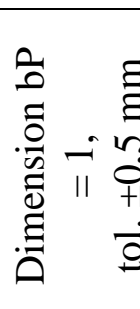 & 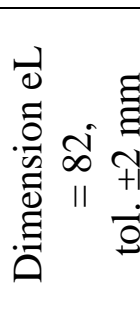 & 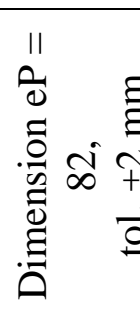 & 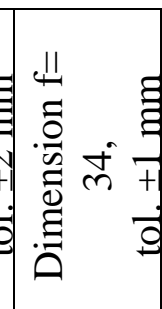 \\
\hline 1 & $+0,35$ & $+0,79$ & $-0,14$ & $-0,14$ & $+1,61$ & $+1,32$ & $-0,41$ \\
\hline 2 & $+0,86$ & $+1,25$ & $-0,01$ & $+0,45$ & $+1,71$ & $+2,06$ & $-0,39$ \\
\hline 3 & $+1,76$ & $+1,31$ & $+0,94$ & $+0,78$ & $+2,71$ & $+1,82$ & $-0,12$ \\
\hline 4 & $+0,48$ & $+1,62$ & $+0,04$ & $+0,44$ & $+1,93$ & $+1,57$ & $-0,48$ \\
\hline
\end{tabular}

In table 5, the real deviations of the remaining tolerated lengths are compared to which, however, no major discrepancies were found. However, one can notice a clear regularity in the distribution of deviations. However, when analyzing small deviations from the nominal diameter of the wire, all of which are positive, the thickness of the anti-corrosion coating in the form of black paint should be taken into account.

Tab. 5: List of other dimensions (not covered by incomplete testing according to the guidelines of PKP PLK S.A.)

\begin{tabular}{|c|c|c|c|c|}
\hline $\begin{array}{c}\text { Clip } \\
\text { numb } \\
\text { er }\end{array}$ & 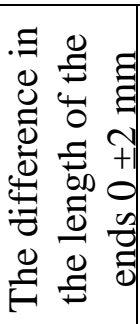 & 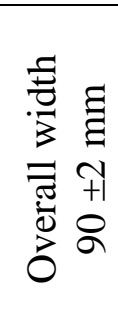 & 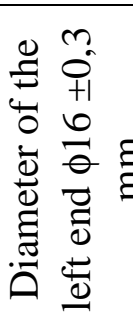 & 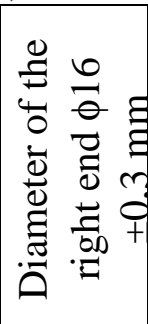 \\
\hline 1 & & -1, & & \\
\hline 2 & $+0,38$ & $-1,79$ & $+0,05$ & $+0,06$ \\
\hline
\end{tabular}




\begin{tabular}{|l|l|l|l|l|}
\hline 3 & $+0,45$ & $-1,74$ & $+0,09$ & $+0,04$ \\
\hline 4 & $+1,14$ & $-1,93$ & $+0,04$ & $+0,06$ \\
\hline
\end{tabular}

\section{Conclusions and directions for further work}

The proposed method of non-contact measurements, consisting in the use of an appropriate optical 3D scanner and software for dimensional quality control, is ideal for measuring such elements as elastic clips of various types, used in rail attachments. The use of contact methods for this type of element is quite problematic or virtually impossible, as in the case of measuring the bending radii of the wire into spatial and tangent arcs. The developed, partially automated scanning procedure along with the processing of results, enables effective and efficient measurements of all dimensions defined in the technical documentation. It also applies to a larger series of elastic clips, which favors the extension of the scope of further research.

The tests carried out show that the dimensions subject to control on the basis of the incomplete examination protocol, specified in the documentation of PKP PLK S.A. [4] are mostly preserved. Also, the curves of the arches referring to the profile of the clips are within the permissible tolerance field.

On the other hand, the radius of arches in the frontal area of the clips is incompatible, the shape of which has been somewhat simplified in relation to the geometry specified in the technical documentation. The nature and size of these discrepancies suggest that they are not accidental, but result from deliberate changes of the manufacturer, consisting in the simplification of the structure for technological reasons. However, significant differences in the version consistent with the nominal geometry and the version consistent with the real geometry of SB4 clips have not been included in the literature so far and may affect the results of many authors in such areas of mechanics as strength, material fatigue, and vibrations. The geometrical discrepancy found, consisting in the simplification of arcs in the frontal area of the clip, until the elimination of two inflection points at the arc joint, may have an effect on stiffening or reducing the elasticity of the actual clip structure with respect to the construction assumptions. Therefore, the authors consider it reasonable to continue research on the impact of this incompatibility on mechanical properties and consequently on the geometry, dynamics, and stability of the railway track.

It may also be appropriate to carry out analogous tests for structurally similar elastic clips type SB7, which are now interchangeably used on modernized sections of railway lines. Perspective geometry studies of a significant population of one of the types of clips would allow a metrological analysis of measurement uncertainty. In addition, the aim of further research by the authors is an operational observation of a specific series of clips, on a route with a known load of transport, to compare their geometrical deviations, before and after the period of presence in the railway track.

\section{Source materials}

[1] Chudyba Ł.: Sprężyste systemy przytwierdzeń do podkładów strunobetonowych porównanie cech eksploatacyjnych systemów przytwierdzeń SB oraz W14. Przegląd Komunikacyjny 11/2017, s. 27-32.

[2] Grulkowski S., Kędra Z., Koc W., Nowakowski M.J.: Drogi szynowe. Wyd. Politechniki Gdańskiej, Gdańsk 2013.

[3] https://solidedge.siemens.com/en/solutions/users/designers-and-engineers, (dostęp 24.09.2018)

[4] Id-109. Warunki techniczne wykonania i odbioru łapek sprężystych i sprężyn przytwierdzających szyny do podkładów i podrozjazdnic. PKP PLK S.A, Warszawa 2010 . 
[5] Lakuši S., Haladin I., Ahac M.: The effect of rail fastening system modifications on tram traffic noise and vibration. Hindawi Publishing Corporation, Shock and Vibration, Article ID 4671302, Vol. 2016, p. 15. https://www.hindawi.com/journals/sv/2016/4671302/ (dostęp 24.09.2018).

[6] Lipko C.: Systemy przytwierdzeń sprężystych - przegląd, wymagania, badania. Infraszyn 2009. Wydawnictwo Naukowe ITE-PIB Radom 2009, s.216-240.

[7] Oczykowski A.: Badania i rozwój przytwierdzenia sprężystego SB. Problemy Kolejnictwa, Zeszyt 150, tom 54, 2010, s.121-156.

[8] Papp H., Liegner N.: Study of longitudinal restraint of rail fastenings. Conference Young Scientist, January 2017, p.5

[9] Romero M.J.G., Edwards J.R., Barkan Ch.P.L., Wilson B., Mediavilla J.: Advancements in fastening system design for North American concrete crossties in heavy-haul service. AREMA 2010 Annual Conference \& Exposition, 2010, p.24.

[10] Sadeghi J., Fesharaki M., Khajehdezfuly A.: Influences of train speed and axle loads on life cycle of rail fastening clips. Transactions of the Canadian Society for Mechanical Engineering, Vol. 39, No. 1, 2015, p. 11.

[11] Towpik K.: Infrastruktura transportu szynowego. Oficyna Wydawnicza Politechniki Warszawskiej. Warszawa 2017.

[12] Vilotijević M., Popović Z., Lazarević L.: Performance requirements for rail fastening systems on European railway network. XVII International Scientific-expert Conference on Railways RAILCON '16. Serbia, Niš, October 13-14, 2016, pp. 137140.

[13] Walino H. K. : Fatigue analysis of the rail fastening E-Clamp on AA-LRT. A thesis submitted to the School of Mechanical \& Industrial Railway Stream. Addis Ababa University 2016, p.82.

[14] Wei J., Liu Ch., Ren T., Liu H., Zhou W.: Online condition monitoring of a rail fastening system on high-speed railways based on wavelet packet analysis. Sensors 2017, 17, 318, pp.2-12.

[15] www.gom.com/pl/oprogramowania-3d/gom-inspect.html, (dostęp 24.09.2018)

[16] www.gom.com/pl/systemy-pomiarowe/atos/atos-triple-scan.html, (dostęp 24.09.2018)

[17] Xiao H., Wang Jia-Bin, Zhang Yan-Rong : The fractures of e-type fastening clips used in the subway: Theory and experiment. Elsevier, Engineering Failure Analysis 81, 2017, pp. 57-68. 